\title{
Funciones del director comercial en empresas familiares: estudio en Cataluña y Barranquilla
}

\section{Commercial directors' functions in family enterprises: study conducted in Cataluña and Barranquilla}

\author{
Stefanu-Lidorikiotu, Yanna \\ Universidad de Barcelona, Barcelona, España. \\ Valdivia-Ubeda, Antonio \\ Universidad de Barcelona, Barcelona, España. \\ Navia-Núñez, Marcela \\ Infocaribe, Barranquilla, Colombia.
}

\section{Autores de Correspondencia}

yanna@av-consultores.com antonio@av-consultores.com contacto@infocaribe.info

Recibido: 27-09-18

Aceptado: 14-12-18

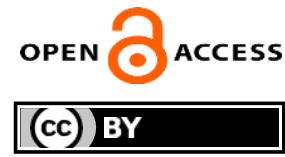

Copyright (C) 2019

Desarrollo Gerencial

\begin{abstract}
Resumen
Objetivo: Conocer las funciones de los directores comerciales en el día a día. Método: Se realizó un estudio cualitativo, con entrevistas en profundidad, en 40 empresas familiares de Cataluña (España) y ocho de Barranquilla (Colombia) para compararlas y encontrar similitudes y diferencias entre ambas culturas. Resultados y discusión: La investigación encontró que en las compañías familiares el director general tiene fuerte injerencia en las decisiones del director comercial, sobre todo si el director comercial no es miembro de la familia propietaria. Se identificó que el director comercial ejerce muchas funciones del área de mercadeo. En Cataluña se halló que cuando el director comercial no es miembro de la familia, el departamento de mercadeo suele depender de la dirección general, en lugar de la dirección comercial. En Barranquilla hay menor propensión al control del equipo de ventas; se prefiere motivarlo. Conclusiones: Los directores comerciales de las empresas familiares dedican mucho de su tiempo y esfuerzo a las gestiones de corto plazo, aunque en Barranquilla hay mayor tendencia a realizar actividades estratégicas.
\end{abstract}

Palabras clave: Funciones del director comercial, empresas familiares, orientación al mercado, organización comercial, estrategia comercial.

Clasificacion JEL: M12, M14.

\begin{abstract}
Objective: this paper aims to know those every-day functions of commercial directors. Method: 40 family enterprises, in Catalonia (Spain), and 8 in Barranquilla (Colombia) were sampled through a qualitative research, using in-depth interviews, was conducted. Results and discussion: This research found how important is the role played by the CEO in commercial decisions, even if this CEO is not a member of the owner family; it was also found, that in this case, the commercial director has several marketing functions. In Catalonia, per example when the CEO is not a member of the owner family, marketing department depends on the general direction department, rather than the commercial. On the other hand, in Barranquilla, when the CEO is not a member of the owner family, less control over sales department is evident. Conclusions: As conclusions, it was found that commercial directors are more committed on, managing their time and efforts to short term management. In Barranquilla, though, they are more commitment on design commercial strategic activities.
\end{abstract}

Key words: commercial director's functions, family enterprises, marketing orientation, commercial organization, commercial strategy.

JEL Classification: M12, M14.

Como citar este artículo (Apa):

Stefanu-Lidorikiotu, Y., Valdivia-Ubeda, A. y Navia-Núñez, M. (2019). Funciones del director comercial en empresas familiares: estudio en Cataluña y Barranquilla. Desarrollo Gerencial, 11(1), 33-59. DOI: https://doi.org/10.17081/dege.11.1.3292 


\section{Introducción}

En el trabajo de consultoría en mercadeo se ha encontrado que muchas empresas quieren vender más y eso lleva a hacer diagnósticos del área comercial de la empresa; se ha observado que los directores realizan funciones muy distintas. Esta investigación pretendió ahondar en el tema para conocer las funciones que realmente ejercen los directores comerciales en su trabajo diario y cómo las llevan a cabo. Se centra en empresas familiares por su tradición en la sociedad, peso en la economía y porque se quiso estudiar qué tanto cambian los tipos de funciones del director comercial dependiendo de si hay parentesco o no con la familia propietaria.

Con respecto a la evolución del rol del director comercial, Artal (2016), basado en Manning y Reece (1997) señala que en el siglo XIX la venta era persuasiva; se debía vender lo producido en las fábricas. En 1950 comienza a pensarse en que el vendedor debe averiguar qué quiere el cliente. En los años setenta se habla de segmentación y los vendedores se transforman en consejeros. En los ochenta aparecen herramientas de organización como el plan de mercadeo y de ventas. En los noventa se trata a los compradores como socios. En la década del 2000 aparece un mayor uso de la informática y la aplicación de ciencias como la psicología pero también hay mayor globalización económica, lo que hace que las ventas sean más difíciles para la pequeña empresa, asimismo el director comercial debía ser capaz de percibir y provocar cambios de forma acelerada. Todos estos procesos se fueron transmitiendo de generación en generación.

De este modo, se quiso conocer cómo se desarrollan las funciones del director comercial de empresa familiar en la práctica. Para el presente estudio se entrevistaron a cuarenta directores comerciales de empresas familiares en Cataluña (España) y a ocho en Barranquilla (Colombia); así, se pudo hacer un comparativo entre ambos lugares. Se escogió metodología cualitativa para estudiar el contexto en que se desenvuelven los directores y tener su percepción de cómo definen su propio puesto de trabajo; a la vez, se incluyó una lista de funciones ayudada para contrastar con la espontánea y con lo hallado por diferentes autores; tras cada elemento de la lista ayudada se indagó si se hace o no en la empresa, quién y cómo la efectúa. Aunque el estudio abarca dos lugares y en dos continentes, hay limitación geográfica. Por ser un estudio cualitativo, es un análisis de caso más que generalizable a la población.

A continuación se analizan algunos conceptos como el puesto del director comercial, sus funciones y las características de la empresa familiar. Se explica la metodología. El perfil de los entrevistados se presenta en secciones separadas, primero de Cataluña con sus respectivos resultados y luego de 
Barranquilla. Seguido a eso, la comparación entre ambos lugares, la discusión de resultados con respecto a otros autores e investigaciones y finalmente las conclusiones.

\section{Fundamentación teórica}

\section{El puesto del director comercial.}

Stanfford \& Grant (1994) definen el puesto del director de ventas como "hacer funcionar el equipo"; añaden que su tarea es "generar ingresos para su empresa mediante las operaciones que realiza el equipo de ventas del que es responsable" (p.25).

Existen discusiones acerca de que si el director de ventas y director comercial son lo mismo y si la dirección de ventas pertenece a la de mercadeo o viceversa. Artal (2016) afirma que "la dirección de ventas es una de las partes importantes de la función comercial-marketing". Además indica que "el director de ventas realiza sus objetivos por medio de unas actividades que básicamente se pueden agrupar en tres áreas: la estratégica, la gestionaría y la de control" (p. 46).

Estratégica se refiere a fijar objetivos y planes para alcanzarlos; así como actividades encaminadas a conocer mejor a los clientes y la forma como se reparten los objetivos entre los distintos vendedores. Gestionaría tiene que ver con el entorno, la mezcla de mercadeo, la dirección y la fuerza de ventas; se trata de administrar la fuerza de ventas. El director debe conocer el producto, formar y motivar a su equipo; debe ser buen negociador y, por supuesto, saber vender. En cuanto al control, se ejerce sobre resultados, comportamientos de los vendedores frente al cliente, costes y rentabilidad; siendo resultados las ventas mismas.

Al respecto, Guiltinan, Gordon y Madden (1998) explican que "a mediados del siglo XX, el término marketing se veía como más o menos equivalente al término ventas". "Sin embargo, cuando los productos se volvieron más sofisticados, el aumento de los ingresos personales permitió la compra de artículos más selectivos, la competencia comenzó a incrementarse y el entorno del negocio se fue volviendo más complejo" (p. 5). Se hizo necesario investigar el mercado para conocer las motivaciones de los consumidores. Fue así como ventas quedó bajo el cobijo de mercadeo: se establece la estrategia de mercadeo y, a partir de ello, los objetivos de ventas. Los autores aclaran que el objetivo debe orientar a los vendedores acerca de cómo identificar oportunidades de ventas y no solamente al volumen. 
Por otra parte, García (2009) define la dirección de ventas como un "proceso de establecimiento de estrategias, fijación de objetivos, ejecución y control de planes de ventas" (p. 53), que busca cumplir objetivos comerciales acordes con los planes de mercadeo. En la actualidad, plantea la necesidad de aplicar nuevas tecnologías y canales, así como gestionar categorías para responder al papel del consumidor. Valdivia (2011, p. 178) cita a Santeases (1999) quien equipara la dirección comercial a la dirección de mercadeo, siempre y cuando se trate de una empresa orientada al mercado, que se toma como una en que el mercadeo está en el centro de las decisiones. Best (2007) citado por Valdivia (2011) señala que las empresas orientadas al mercado son las que tienen contacto permanente con las necesidades de sus clientes, las estrategias de la competencia y el entorno; buscan adaptarse a ello. Páramo (1998) cita a Narver \& Slater (1994) para indicar que la orientación al mercado abarca una orientación al cliente, a la competencia y una coordinación entre visión de largo plazo y rentabilidad. Para medir la orientación al mercado estos autores formulan el interrogante de si las utilidades se miden por segmento del mercado y si hay políticas de servicio posventa, entre otros puntos. Así, lo importante es considerar que ventas y mercadeo van de la mano y efectivamente pueden considerarse como equivalentes director comercial y director de ventas.

\section{Funciones del director comercial.}

Diez, Navarro y Peral (2003), basados en Strafford y Grant (1994), indican que las funciones de la dirección de ventas son: planificación, organización, reclutamiento, formación, motivación, control y seguimiento. Igualmente, Díez et al. (2003), basado en Rubio (1999), señalan unas funciones en el campo estratégico: organización, dirección y motivación de la fuerza de ventas, selección, ejecución de planes de formación, fijación de cuotas de venta, establecimiento de incentivos, configuración de territorios de venta, control de resultados, análisis de servicio posventa y elaboración de argumentos. Explican que hay otras funciones que puede cumplir el director comercial o una persona de un nivel más bajo en el organigrama como un jefe; tales como gestionar cobros y despachar pedidos.

Strafford \& Grant (1994) mencionan otros temas como control presupuestario, mejora del margen de venta, manuales de venta, venta en ferias, investigación de mercados, relaciones públicas, tratamiento de reclamaciones, lanzamiento de productos y preparación de ofertas con precio y condiciones; aclaran que algunas se dan si el director de ventas ejecuta la actividad de mercadeo también.

Por otra parte, Valdivia (2011) cita a Churchill, Ford y Walker (1994), quienes agrupan las funciones en estrategia, puesta en práctica y evaluación. En el primer aspecto incluyen política de gestión de cuentas, 
planificación de cuotas y de presupuestos, además del diseño territorial con sus respectivas rutas. En la puesta en práctica contemplan supervisión, formación y motivación.

Para evaluar tienen en cuenta análisis de ventas, costes y comportamiento. Labrado (2006, p. 60), también citado por Valdivia (2011) considera que las responsabilidades del director comercial son: "definir los objetivos comerciales de la empresa, diseñar políticas estratégicas para cada producto y para cada mercado: precios, condiciones de venta, canales de distribución, publicidad, promoción, etc."; elaborar presupuestos; dirigir la red comercial: reclutamiento, formación, incentivos y motivación; "negociar contratos comerciales con grandes clientes"; diseñar el plan de mercadeo y establecer planes de publicidad y promoción (p.70).

Además, Voirin (1998) agrupa en nueve las responsabilidades del director comercial y de mercadeo: política comercial (tipos de descuento, plazos de pago, etc.); marketing (mezcla de mercadeo, nuevos productos, comunicación, campañas de promoción); desarrollo (ejes del plan estratégico, vigilar calidad de productos); dirección de ventas (seguimiento, formación del personal, supervisar la organización de las visitas a clientes, organizar cartera de clientes directos, estudios de solvencia de clientes); presupuesto (de ventas, comisiones, informes a dirección general); secretariado comercial (seguimiento de los vendedores, documentación); administración de ventas (supervisar pedidos, que se respeten los plazos); calidad (exigencias del cliente); otros (participar del comité de dirección). Como se puede apreciar, más que una lista de funciones, los diferentes autores agrupan en temarios, lo que muestra la complejidad del cargo.

\section{La empresa familiar.}

Lozano, Romero \& Hirsh (2017) apuntan que la historia de las empresas familiares se remite a la antigüedad pues desde siempre los padres han enseñado sus oficios a los hijos. Sin embargo, Omaña y Briceño (2013) anotan que "el campo de estudio de las empresas familiares se remonta apenas a 1975, cuando el Dr. León Danco publicó su obra pionera, A Guide for the Business Owner and His Family" ( $p$. 294). También indican que de acuerdo con Serna y Suárez (2005) la participación de las empresas familiares en la economía colombiana es de $65 \%$ y en la española de $71 \%$.

En otro orden de ideas, Sánchez (2004) define una empresa familiar como "cualquier empresa dirigida por miembros de una familia, que son sus propietarios" (p. 29). Guinjoan, Murillo y Pons (2004) precisan que: "Se entiende por empresa familiar aquella empresa que pertenece de una manera continuada en el 
tiempo a personas de un círculo familiar y que es dirigida por uno o más de los miembros de este círculo" (p. 14).

Molina, Botero y Montoya (2016) hacen un análisis teórico de las definiciones de empresa familiar. (p.120). Gallo (2004) afirma que una empresa familiar se caracteriza porque el poder de decisión está en una familia, las responsabilidades de gobierno y dirección son desempeñadas por algunos de sus miembros y como mínimo algunos integrantes de la segunda generación están incorporados en la empresa; aclarando que no hay una definición unificada para estos autores ni para muchos otros.

Díaz, Leal y Urdaneta (2018) explican que algunos de los problemas de las empresas familiares según Vainrub (2006) son "dificultades con la continuidad, estatismo en la estructura organizativa y conflictos entre los miembros familiares y los no familiares" (p.115).

Para terminar, Gallo (2004) refiere diferentes modelos para tipificar las empresas familiares, por ejemplo muestra cuatro tipos según tamaño y diversificación; usa árboles como símbolos: 1) Bonsai, empresas pequeñas que cambian poco a lo largo de los años. 2) Árbol solitario, han crecido pero siempre en el mismo sector o con una gama muy limitada de productos. 3) Bosque, crecen por su diversificación geográfica y han adaptado sus productos a nuevos mercados. 4) Selva tropical, empresas de elevado crecimiento en nuevos mercados y con nuevos productos.

\section{Método}

\section{Diseño y participantes.}

Valdivia (2011) desarrolló una etapa inicial del presente estudio con una investigación cualitativa con la técnica de entrevista en profundidad, aplicada a 40 directores comerciales de empresas familiares en Cataluña (España).

Director comercial se tomó con base en la definición de Santesmases (1999):

La dirección comercial, como una de las direcciones funcionales que dependen de la dirección general, es la encargada de facilitar y llevar a cabo la actividad comercial de la empresa. La dirección comercial será dirección de marketing si se apoya en el concepto actual de marketing y está orientada al mercado, es decir, si tiene el mercado como centro de sus decisiones. (p. 99) 
Se usó metodología cualitativa para tratar de identificar "la naturaleza profunda de las realidades, su estructura dinámica, aquella que da razón plena de su comportamiento y manifestaciones" (Martínez, 2006, p.66). Como indica Fassio (2018) basada en Bryman, 1995, la investigación cualitativa se puede aplicar a las organizaciones para tomar el punto de vista interno y se llega con una visión desestructurada, sin hipótesis previas.

\section{Procedimiento e instrumentos.}

En la entrevista se solicitó al director que describiera su puesto de trabajo, luego que comentara cuáles eran las funciones y tareas a las que se dedicaba en su tiempo; estos dos aspectos se indagaron de forma abierta y espontánea. Después se preguntó por unas funciones específicas, es decir, de manera ayudada; se indagó si en la empresa las realizaban y en caso afirmativo de quién era la responsabilidad de dicha función y cómo se desarrollaba. Así, aunque se usó una lista ayudada, basada en las principales funciones descritas por diferentes autores para el puesto, se profundizó en la percepción del director comercial hacia cada una de dichas funciones. El instrumento fue revisado por expertos para verificar su validez interna.

La misma guía de entrevista se aplicó en Barranquilla (Colombia) en el segundo semestre de 2016 a ocho directores comerciales de empresas familiares. Estas personas de ambos países, a su vez, participaron en otro estudio sobre decisiones empresariales. Para escoger las empresas se preguntó al momento de hacer la cita si se trataba de una empresa familiar; ya en la práctica se dieron diferentes situaciones con respecto al papel de la familia propietaria que se explican en el apartado de perfiles de cada localización. La empresa podía ser de cualquier tamaño y sector económico; adicionalmente, podía contar con sede principal en la zona o una regional donde se tomen decisiones estratégicas. Igualmente, se preguntó por el responsable de la planificación, administración y control del personal de ventas, independientemente del nombre exacto del cargo. Algunas empresas fueron descartadas porque el puesto de director comercial quedó vacante o un caso en que prefirió no participar por considerar que carece de fuerza de ventas, aunque para efectos del estudio si una sola persona lo hacía, era válido, pues la idea era tener acceso a diferentes situaciones.

En el presente artículo hay un análisis de resultados en cada país y un análisis comparativo en lo referente a funciones del director comercial. Dicho análisis se realizó de manera directa e interpretativa, por ser un estudio cualitativo; aunque en algunos casos se consideró importante hacer algunos conteos como en una tabla resumen que se presenta, dado que podía ser más claro para el lector. Previamente, 
se realizó transcripción literal de las entrevistas (fueron grabadas en audio) y categorización de las respuestas abiertas.

Es así como el valor del estudio estriba en que se analizó el trabajo ejecutado por el director comercial en el día a día, no el deber ser. Por otra parte, la metodología cualitativa ayuda a entender el contexto de cada empresa. Con las preguntas abiertas y espontáneas se evitan sesgos; como también se tuvo una lista posterior ayudada, permitió comparar los resultados con análisis previos, por lo general teóricos, pues no se encuentran muchos trabajados aplicados específicamente a este cargo en empresas de origen familiar. Por todo lo anterior, puede decirse que se usó un paradigma constructivista, pues buscó interacción social y considerar que hay diferentes puntos de vista o percepciones (Ramos, 2015, basado en Flores (2004).

\section{Perfil de los entrevistados y las empresas en Cataluña, España.}

Por tamaño de empresa, se tiene que casi la mitad tienen entre once y cincuenta empleados; también hay una cantidad importante con un número entre cincuenta y uno y doscientos cincuenta empleados, pero también hay unas pocas, de diez empleados o menos y de más de doscientos cincuenta empleados. Casi la mitad cubre el mercado nacional; otra buena parte, el regional y unas pocas venden a otros países. Se dividen casi a partes iguales entre entrevistados que son miembros de la familia y los que no lo son. Prácticamente la mitad posee estudios de posgrado.

Se encontró que en dieciocho de las cuarenta empresas el cargo del entrevistado es director comercial; en cinco empresas el director comercial a la vez es el propietario; los demás corresponden a diferentes cargos como vicepresidente o responsable de ventas. En veintidós empresas hay departamento de mercadeo; en la mitad de los casos depende de la dirección comercial y en la mitad, de la dirección general. De las once empresas en las que el departamento de mercadeo depende de dirección comercial, en tres casos el director comercial no forma parte de la familia; de las once empresas en las que mercadeo depende de dirección general, en diez casos el director comercial no pertenece a la familia. 


\section{Resultados en Cataluña.}

Al describir el cargo de director comercial de manera espontánea, los entrevistados fueron clasificados en cinco grupos:

a) 'Hago un poco de todo'; Valdivia (2011) encontró dentro de éste dos posiciones: los que se quejan por considerar que sus tareas no corresponden a su función de director comercial -que no son miembros de la familia- y otros que lo toman de forma positiva; si no son miembros de la familia porque consideran que es una situación inherente a las empresas familiares y si son miembros de la familia porque sienten responsabilidad por todo el negocio.

b) Responsable de la venta; que son personas enfocadas a resultados, bien sea en ventas o en rentabilidad.

c) Enfocado al equipo comercial; son directores que enfatizan en el apoyo o en el control al equipo de ventas.

d) Vender y hacer que se venda; se refieren a la gestión del equipo de vendedores y cuentan con su propia cartera de clientes.

e) Gestor; resaltan la gestión del producto, la cartera de clientes, del equipo comercial o del mercado. Se observa que este último grupo busca ser proactivo; intenta que sucedan cosas en vez de esperar a que lleguen.

Por otra parte, las funciones que los entrevistados nombraron de forma espontánea se agrupan en las categorías: administrativa, planeación, control, mercadeo, comunicación externa, vendedores y clientes; por área la más nombrada fue vendedores, seguida de mercadeo. La función a la que más se dedican los directores comerciales entrevistados en Cataluña es captar nuevos clientes; relacionadas con clientes también están: gestionar clientes propios, hacer seguimiento a clientes actuales, visitar clientes, entre otras. A lo que se suman las asociadas a vendedores donde también está el tema de visita pero como acompañamiento a los vendedores; además de supervisar vendedores, gestionar la fuerza de ventas, apoyo a vendedores y unas con menos menciones como seleccionar, motivar y comunicarse con vendedores.

Dentro de la categoría administrativa están: elaborar reportes, reuniones con otros departamentos y reuniones con gerencia; una persona explicó que una de sus funciones es buscar proveedores. En la de planeación hay temas como establecer objetivos de ventas y elaborar presupuestos. Otro grupo de tareas son de control: controlar presupuestos, seguimiento a proyectos, control de la planeación y los cobros, 
entre otras. De la categoría de mercadeo, los directores comerciales ejercen varias actividades relacionadas con investigación (aunque con pocas menciones): estudiar el mercado, estudiar el mercado con lo que se ve en la calle y lo que hace la competencia, seguimiento a vendedores para recoger información del mercado, análisis de datos del mercado, detectar oportunidades en el canal, visitar ferias para conocer el mercado; también con competencia: precios, productos nuevos, cómo se posiciona, entre otros.

Como estrategia están: estrategias de mercadeo por productos y segmentos, por cliente y marca, innovadoras según lo que hace la competencia y demanda el mercado, para vender más, para exportar a nuevos mercados, fijar estrategias de precios, preparar el plan de mercadeo, campañas y promociones. Específicamente con comunicación externa hay temas como manejar la página Web y sacar catálogos y folletos.

Con una lista de funciones mostrada de forma ayudada, se encontró que las que más se hacen en las empresas contactadas son: organización del departamento comercial, sistemas de control y evaluación, sistemas de retribución, análisis y gestión de cartera de clientes, selección y contratación de vendedores, comunicación externa, análisis y seguimiento de la competencia y establecimiento de objetivos. Las que menos se desarrollan en las empresas son: manual de ventas e informes comerciales para la gerencia.

De igual modo, Valdivia (2011) encontró que las funciones que se realizan en casi todas las empresas están orientadas a la acción, como gestionar la red comercial; en más de la mitad de las empresas se halló que se ejecutan funciones relacionadas con un enfoque analítico y estratégico como seguimiento de la competencia y establecimiento de objetivos; en menos empresas se da un grupo de funciones relacionadas con la posventa, segmentación del mercado, diseño de argumentos de ventas, manuales e informes.

Las funciones que más recaen en el director comercial son apoyar al equipo de ventas y establecer sistemas de control. El director general suele involucrarse principalmente con los sistemas de retribución, establecimiento de objetivos, la organización del departamento y la comunicación externa. Se identificó que se da una mayor interferencia en las funciones del director comercial cuando éste no es miembro de la familia que regenta el negocio.

En cuanto a la competencia, se encontró que en casi la mitad de los casos se hace con base en los datos recogidos por el equipo comercial. Otros buscan en la Web y establecen contactos con proveedores; 
en seis empresas hacen investigación de mercado. Establecer objetivos de ventas es función del director comercial y en muchos menos casos del director general o del comité de dirección. Lo más común es establecer los objetivos con una discusión con los subordinados. Otra tendencia es establecer estrategias comerciales a mediano plazo, aunque hay muchos que las van fijando conforme surgen las necesidades. En cuanto a la organización del departamento, lo más usual es que la hayan establecido hace algún tiempo pero no la revisen periódicamente; también hay casos en que se hace de forma activa y otro número importante lo hace como vaya surgiendo según las demandas del mercado.

Se halló que la retribución comercial más común se hace con un sueldo fijo más variable por comisión. Los directores comerciales suelen apoyar al equipo comercial con acompañamiento en visitas, reuniones informales o formales y motivación. El control lo ejercen con un parámetro cuantitativo primordialmente al hacer seguimiento de la cifra de ventas; además, una buena parte fija otros criterios como número de clientes nuevos conseguidos y número de visitas realizadas. La principal actividad que hacen en el tema de comunicación externa es publicar catálogos y folletos. La mitad de las empresas contactadas no cuentan con encargados de atención al cliente y en varios casos consideran que la visita rutinaria de ventas cumple a la vez con esa función; seis empresas controlan la calidad del servicio por medio de encuestas. Otro hallazgo fue que la mayoría de empresas no cuenta con un sistema de CRM (Customer Relationship Management) pero varios tienen programas que permiten algún tipo de seguimiento al cliente o de administración general.

\section{Perfil de los entrevistados y las empresas en Barranquilla, Colombia.}

El perfil de los entrevistados para el caso de Barranquilla, Colombia, fue: cinco de los ocho son miembros de la familia; de ellos, tres son de segunda generación y dos son fundadores. Solo una mujer es la encargada del área comercial, ella y otro de los que son hijos de los fundadores manejan el área de compras, además de ventas. En este sentido, de los que son miembros de la familia, dos, son fundadores, uno de los cuales tiene como asistentes a su esposa y a su hijo, y el otro fundó la empresa con dos hermanos; dos más son hijos del dueño y en la empresa trabajan otras personas de la familia. También está la figura de un yerno de la dueña, cuya esposa tiene el cargo de jefe de compras pero para efectos prácticos ella opera como subgerente; una prima de él tiene otro cargo directivo. Entre los que no son miembros de la familia, está un caso en que la compañía surgió de la fusión de dos empresas familiares; cuando se hizo la unión, las dos familias tomaron la decisión de no ocupar cargos y nada más representan en la junta directiva. 
De los ocho entrevistados, seis ostentan cargo de director o gerente comercial aunque a veces con otro nombre como gerente de negocios, de una unidad de negocio o de una región específica; los otros dos son gerentes generales -con las funciones comerciales- y fundadores. Todos los entrevistados culminaron estudios superiores (como ingeniería industrial o administración de empresas); además, seis cuentan con estudios de posgrado, en su mayoría, afines a mercadeo.

En cuanto al perfil de las empresas familiares abordadas, hay una microempresa, una pequeña empresa, cuatro medianas y dos grandes. Dedicadas al comercio, hay seis de las cuales cinco un fuerte componente en servicios (instalación de software, ensamble, mantenimiento, asesoría, corte de piezas en acero); las otras dos son fábricas (de alimentos e industria química). La empresa más joven cuenta con ocho años de existencia y algunas fueron creadas hace más de cincuenta años. La microempresa tiene al gerente general en el área comercial y dos personas que no son empleadas y ganan comisiones; esta figura la tienen las dos empresas grandes también pero solo para casos específicos: la una para fuera del país y la otra para negocios de gran tamaño. En los demás casos, toda el área comercial está constituida por empleados de la compañía.

La empresa que es netamente comercial (no ofrece servicios adicionales ni fabrica) tiene doscientos de sus trescientos empleados en esta área. Cuenta con veintisiete tiendas en todo el país; tiene dos líneas de negocio con dos marcas y almacenes diferentes. Hay un director comercial para cada una; una es miembro de la familia (la entrevistada) y otro que no es miembro de la familia. En otro caso están setenta de los doscientos cuarenta y nueve empleados en el área comercial; allí hay siete directores comerciales, uno para cada región del país. Las dos fábricas cuentan con siete y diez empleados en el área comercial; las otras empresas tienen números más o menos como esos y hasta veinte. Hay una que vende un producto industrial y cuenta con un esquema de un vendedor principal y un asistente para cada región, todas manejadas desde la sede principal (Barranquilla); el asistente se encarga de la papelería, además hay tres vendedores de mostrador en el único local que poseen, que también está en Barranquilla. En la industria de alimentos, el personal de ventas está ubicado en supermercados para invitar a clientes a probar y llevar el producto. En la empresa que vende computadores y similares todos se consideran del área comercial, incluyendo al gerente-dueño y padre del gerente comercial- y a las personas que venden en mostrador en puntos de venta. Nada más dos empresas cuentan con alguien de mercadeo; en un caso depende del área comercial, en el otro, de la gerencia general pero es muy operativo, pues está constituido por una sola persona, cuya función es proveer material publicitario. El mercado de casi todas es la región del país cercana a su sede (Caribe), además una vende en el sur del país, dos a nivel nacional en general y una exporta a países de América y Europa el $40 \%$ de su producción. 


\section{Resultados en Barranquilla.}

Los directores comerciales describen de forma espontánea su puesto con las siguientes ideas:

Relacionadas con ventas:

a) Resultados en ventas/ incrementar volumen de ventas,

b) Contacto, motivación y gestión a vendedores [es la respuesta más popular],

c) Velar por comunicación oportuna entre vendedores y clientes, que eso se convierta en una cotización y venta.

Labores administrativas:

d) Diseñar presupuestos y descuentos/ velar porque la sucursal sea rentable,

e) Contacto con otras áreas como investigación y desarrollo, compras y planeación,

f) Velar por cumplir promesa de valor: tiempo, cantidad y calidad.

Sobre el producto:

g) Buscar que el producto rote,

h) Conocer el producto.

Afines a mercadeo:

i) Posicionamiento de marca,

j) Estar atento a los competidores y buscar diferenciación,

k) Diseñar ofertas y promociones.

Acciones con el cliente:

I) Mantenimiento de clientes,

m) Metas de clientes nuevos,

n) Relacionarse con clientes,

o) Estar atento al mercado,

p) Las necesidades de los clientes.

Otros:

q) Relación con proveedores,

r) Retador, exige creatividad,

s) Duro y estresante.

Algunos de estos temas se repiten al indagar de forma espontánea por las funciones que ejerce en su cargo de director comercial. Los temas en este caso son de dos áreas: administrativa, y de mercadeo y ventas. En el primer grupo están las siguientes categorías: Estrategia: a) Vigilar la rentabilidad. b) Desarrollar la estrategia de la compañía. c) Incrementar volúmenes de ventas. Compra: d) Compra de productos en el exterior. Control: e) Manejo del presupuesto del área; descuentos. f) Manejo de inventario, rotación de productos, códigos/ rotación de inventario. g) Revisión de ventas con respecto al período anterior; alcanzar metas de ventas diarias/ porcentajes de ventas [respuesta más frecuente]. $h$ ) 
Vigilar que las tareas se cumplan. i) Mejoramiento de indicadores. j) Informes para la gerencia/ reuniones de seguimiento con gerencia.

En cuanto a las funciones relacionadas con ventas y mercadeo hay cuatro categorías:

Vendedores:
a) Visitar puntos de venta,
b) Diseñar incentivos para los asesores,
c) Motivar a los vendedores,
d) Entrenarlos,
e) Hacerles seguimiento y acompañamiento,
f) Supervisarlos,
g) Liderarlos,

Clientes:

h) Identificar necesidades de los clientes,

i) Hacer seguimiento y mantener clientes,

j) Hacer servicio posventa,

k) Atender quejas y reclamos,

l) Buscar nuevos clientes.

m) Estar atento a oportunidades.

n) Elaborar cotizaciones,

o) Visitar o ponerse en contacto con clientes,

p) Hacer promociones,

q) Entender los micromercados y segmentos.

Las otras dos categorías relacionadas con mercadeo son competencia y relaciones públicas: r) Analizar la competencia. s) Atención a gremios.

Así, lo más destacado en la descripción de su propio puesto es la coordinación de los vendedores y la función en la que más piensan es en alcanzar metas de ventas diarias, con lo que se denota que mucho del oficio del director comercial es de control. Las funciones expuestas resultan más de temas del día a día, mientras que la descripción del puesto es más afín a la estrategia -básicamente de mercadeo; es lo que hace comparado con lo soñado. 
Se indagó por unas funciones en particular (mismas por las que se preguntó en Cataluña): si se hace en la empresa y en caso afirmativo, quién y cómo. En total eran diecinueve funciones. Las funciones que más se realizan en las empresas barranquilleras, pues fueron nombradas por todos los entrevistados ante la pregunta ayudada, son: segmentar el mercado, establecer objetivos de ventas, definir estrategias comerciales, organizar el departamento comercial, poseer sistemas de selección, contratación e inducción de vendedores y tener sistemas de control. Segmentar el mercado y establecer objetivos de ventas son realizadas casi siempre por el gerente general y el director comercial, que en algunos casos es la misma persona. La definición de estrategias comerciales, la organización del departamento y los sistemas de control suelen estar más en cabeza del director comercial; aunque un entrevistado de una empresa grande señala que la organización del departamento comercial es responsabilidad "mía, pero como es una empresa familiar tiene que venir con el visto bueno de aprobado del gerente general"; sobre el diseño de sistemas de retribución del área comercial dice que "no se ha podido hacer porque el dueño del negocio lo sabotea. Si él no está convencido de algo, no se hace y punto, por más que le vendas que es muy bueno. Él siente que es dar más plata por lo que ya te estoy pagando". Con ello, se nota la difícil relación entre el director comercial y el gerente general, especialmente cuando el director no es miembro de la familia.

La segmentación del mercado se realiza de una manera natural; por ejemplo, una empresa tiene dos directores comerciales: uno para la línea básica y otro para la línea de lujo; "se segmenta por precio y calidad". Un entrevistado había dicho que no segmenta pero luego cayó en la cuenta que lo hace por canal pues tienen estrategias diferentes para el institucional (restaurantes y hoteles), las grandes superficies y el tradicional constituido por panaderías y carnicerías. En otros casos hay mayor consciencia del proceso, por ejemplo: "cuando segmentamos sabemos qué tipos de clientes son y qué es lo que más están necesitando"; tienen vendedores para segmentos especializados según industria como la minera y también por región, aun cuando todos los vendedores atienden desde la sede principal en Barranquilla.

Sobre los objetivos de ventas, función que había sido nombrada de forma espontánea, hay varias menciones acerca de que se obtienen con base en ventas históricas; está un caso de microempresa que tiene metas para obtener nuevos clientes -por ejemplo, en otras ciudades- y también para sostenerlos, pues una de sus principales fuentes de venta es el mantenimiento del equipo, que también instala. Hay un director que tiene en cuenta más factores como las condiciones del mercado y la economía y los clientes prospecto en sectores económicos que más han ido creciendo. Al indagar cómo se desarrolla esta función, un director comercial explica: "Al ser una empresa familiar, los objetivos cambian cada mañana y cada tarde. El norte lo tienes pero se desvía un poquito muchas veces, porque depende mucho 
culturalmente del dueño; las empresas familiares terminan siendo una extensión de la cultura, del pensamiento del propietario. Seguramente hay muchas empresas familiares donde hay un gobierno corporativo o incluso el gerente general no es de la familia, tienen políticas de familia; en esta compañía no, el dueño en gran parte dictamina qué va a pasar y cómo va a pasar y tú puedes tener tu semana programada para algo pero él te puede -muchas veces- cambiar un poquito tu plan"; por ello, es que esta función tiene fuerte influencia de la gerencia.

Además, hay funciones de la lista ayudada que fueron nombradas también por una buena cantidad de entrevistados como el seguimiento a la competencia. En este punto se encontró que el director comercial lo desarrolla según su estilo de gerencia más que dependiendo del tamaño de la empresa, el tipo de producto o si es miembro de la familia. Muchos se enfocan a precios, pero también hay casos en que hacen seguimientos a los lanzamientos de productos, las ferias, estadísticas del mercado publicadas en prensa y las importaciones. El análisis del servicio posventa se hace llamando o visitando al cliente para conocer qué hace falta o cómo se sintió atendido; en tres compañías hacen encuestas periódicas para medir satisfacción. La comunicación externa se hace con folletos y catálogos, pero en algunos casos es de forma ocasional como cuando se va a participar en una feria. Hay un caso de una empresa en la que decidieron no volver a hacer campañas publicitarias masivas pues consideran que son costosas y poco efectivas, por ejemplo: pautaban en prensa ofreciendo un descuento y la venta era igual a cualquier otro día; "relaciones públicas no hay que hacer por ser muy fuertes en el mercado, con 25 años", así es que les llegan los clientes sin necesidad de buscarlos, sin embargo, como estrategia reciente lanzaron un catálogo especializado para un segmento en particular.

Una de las funciones menos nombradas, entre la lista ayudada, fue la utilización de nuevas tecnologías y en los casos en que se hace es parte de un sistema de toda la compañía donde se incluye, por ejemplo, una forma de cotizar o hacer preguntas por medio de la página Web. De estos sistemas pueden extraerse informes para la gerencia. La otra función que se hace en pocas empresas es desarrollar un manual de ventas.

\section{Comparación resultados de Cataluña y Barranquilla.}

Tanto en Cataluña como en Barranquilla se detectó que los directores comerciales tienden a describir su cargo como responsable de las ventas. La diferencia es que en Cataluña hay mayor inclinación al control del equipo de ventas y en Barranquilla más a la motivación. Otra diferencia es que en Barranquilla 
varios entrevistados perciben su cargo con disposición al producto, el mercadeo y el cliente y este tipo de respuestas no se dieron inicialmente en Cataluña.

Las funciones del cargo mencionadas de forma espontánea en ambos lugares por los directores comerciales entrevistados se parecen en las áreas básicas como administrativa, de mercadeo, relacionadas con clientes y con vendedores (apoyo y control, por ejemplo). Igualmente, en ambas zonas lo más nombrado tiene que ver con la venta misma, aunque en Barranquilla se orienta más a la medición de la gestión y en Cataluña a lo operativo. Se observa que el director comercial ejerce funciones de mercadeo en ambos lugares. Unos de los temas mencionados en Barranquilla y no en Cataluña fueron rotación de inventario y servicio posventa; esto puede tener que ver con que en España mencionan que por la crisis económica han tenido que dedicarse más a mantener clientes y por ello también puede ser que el trabajo sea más operativo y quede menos tiempo para lo estratégico que en Barranquilla, donde no se habla de crisis; aunque en ambos lugares mucho del tiempo se va en actividades del día a día.

La conclusión hallada en Cataluña: 'se identificó que se da una mayor interferencia en las funciones del director comercial cuando el director comercial no es miembro de la familia que regenta el negocio', se validó en Barranquilla. Objetivos de ventas y sistemas de retribución son temas en que el director general tiene injerencia en ambos lugares.

De la lista de funciones ayudada, coinciden en alta popularidad: establecer objetivos, organizar el departamento, poseer sistemas de selección y contratación de vendedores y sistemas de control. Una popular en Barranquilla y no tanto en Cataluña es segmentar el mercado. En ambos lugares la menos popular fue tener manual de ventas y no es común tener un sistema de CRM, a no ser que sea parte de un sistema de administración general.

En Barranquilla se presentaron dos diferencias por una interpretación de los términos: una, gestión de cartera de clientes se asoció inicialmente con el cobro, en cambio en Cataluña se comprendió como portafolio de clientes, entre lo que puede estar el cobro y, la otra, fue que no se tuvo claridad de a qué se refería Plan de Acción Comercial; algunos lo vieron como plan de cada vendedor, otros como la parte táctica de un plan más general y otros no supieron. En España, varios pensaron en un plan anual estratégico y en algunos casos aclararon que ya no se hace porque el mercado es muy cambiante.

En la tabla 1 se puede observar la forma como fueron nombradas las funciones de manera espontánea (tras una categorización). Las expresiones son similares, por ejemplo, en control; en ambos lugares se 
refieren a calidad, presupuestos e indicadores. En cuanto a competencia, hay mayor precisión en Cataluña. Temas como selección de vendedores fueron nombrados de forma espontánea en España pero no en Colombia.

\section{Discusión}

Valdivia (2011, p. 189) comparó los resultados de Cataluña con lo hallado por Strafford \& Grant (1994) y retomados por Diez et al. (2003) y encontró que la función de planificación, entendiendo como tal el establecimiento de objetivos para la fuerza de ventas, se hace en la mayoría de empresas catalanas pero en (3) tres de cada (10) diez casos "recibe interferencias de órganos superiores a la dirección comercial". También halló que todos los entrevistados cumplen actividades de organización, que es otra de las tareas planteadas por los autores. Reclutamiento se da en la mayor parte de los casos y no sucede igual con las funciones de formación pues en la mitad de las empresas no se presentan con regularidad; la parte motivacional fue definida como 'apoyo al equipo de ventas' y se realiza en más de la mitad de los casos. La función de control se considera clave en las empresas catalanas de acuerdo con el estudio.

En relación con Churchill et al. (1994), Valdivia (2011) Valdivia (2011) notó que en la mayor parte de los casos catalanes no se realiza una planificación estratégica en temas como establecimiento de objetivos y gestión de cartera aunque son actividades que se desarrollan sobre el día a día en algunos casos. La parte de poner en práctica el programa de ventas, que reúne temas como formación y apoyo al equipo de ventas, se da en más de la mitad de los casos. Estos autores también plantean la función de control que, como se mencionó, sí se da en las empresas de Cataluña. Algo similar sucede con los planteamientos de Artal (2016), dado que la parte estratégica no está muy presente en la actividad de los directores comerciales, sino que hay una visión más a corto plazo. En cuanto a lo que este autor denomina área gestionaría, se encontró mayor tendencia a aplicar temas de selección y retribución más que de formación y apoyo. Y lo que sí aplica es la función de control.

Con respecto a otros estudios, está el de Canales y Küster (2008) realizado en España con (108) ciento ocho directores de ventas. Se encontró que los directores ejercen funciones de control, por ejemplo, al medir el desempeño de los vendedores; aunque este estudio se centró en el control y no en las funciones en general. Se halló que muchos directores ejercen control sobre el comportamiento de los vendedores y que cuando lo hacen el vendedor se siente más comprometido y tiene mejor desempeño. Las actividades de control al comportamiento de vendedores no fueron mencionadas en el presente 
estudio, ni en Cataluña ni en Barranquilla; el acompañamiento a las visitas del vendedor es para apoyar la venta.

Otro estudio afín fue el realizado por Martín y Cabrera (2007) en Las Palmas (España); su enfoque era la gestión de mercadeo en empresas familiares. Uno de los hallazgos fue que en empresas pequeñas hay menor tendencia a la formalización de la gestión comercial; lo cual es coherente con lo encontrado en ambas localidades (Cataluña y Barranquilla) para el presente estudio. Basco (2010) realizó un estudio en España en empresas familiares; aunque no iba dirigido al director comercial, halló que la familia influye en la empresa y trae comportamientos diferentes que define como ventaja competitiva por poner en práctica procesos inimitables. En el presente estudio se halló una fuerte tendencia del director general a involucrarse en las funciones del director comercial y el ajuste de sus objetivos cuando es miembro de la familia propietaria, lo que muestra su influencia.

Garavaglia y Del Bene (2017) realizaron un estudio similar al presente, dado que hicieron entrevistas en profundidad en diez empresas de Italia y Argentina. Explican que los gerentes que no son miembros de la familia suelen tener autonomía pero dentro de una organización donde el fundador integra, que es parte de lo encontrado en este caso. Otro estudio comparativo y también cualitativo fue el realizado por Pérez (2014) con quince empresas familiares de Cataluña y Chile, más casos por fuente secundaria de México. Pérez encontró en Cataluña que en el papel se menciona separación de familia y empresa pero en la práctica el padre tiene autoridad en ambas esferas y el hijo mayor tiende a ser su heredero en el mando; aspectos encontrados también en esta ocasión.

En un estudio realizado en Tailandia, en comparación con Japón y teniendo en cuenta diferentes orígenes empresariales, Wailerdsak y Suehiro (2004) encontraron que las firmas controladas por familias son renuentes al desarrollo profesional de los gerentes internos; esto no se corroboró en el presente estudio pues se halló que en ambas localizaciones hay directores comerciales con alto nivel de capacitación como maestría y hay promoción interna.

En cuanto a Latinoamérica (específicamente Chile), Bullemore y Fransi (2016) encontraron con un panel de expertos que las compañías de ese país no desarrollan estructuras comerciales, ni diseñan planes y funciones de la fuerza de ventas de manera formal. En la presente investigación se halló estructura en varias empresas, especialmente las de mayor tamaño, pero en varias compañías todos los miembros de la empresa se convierten en comerciales temporalmente. 
En Colombia, Gómez Betancourt, Zapata Cuervo y Betancourt Ramírez (2016) realizaron un estudio en que también encontraron que en las empresas familiares el dueño se encarga de gran parte de las decisiones y hace frente a la gestión cotidiana de la empresa; esto desde la óptica del gerente general. Nuevamente es coherente con lo encontrado en ambos lugares donde se realizó la presente investigación.

En la tabla 1 se puede apreciar un comparativo de lo encontrado en ambos lugares junto con una recopilación de los autores que exponen cada función del director comercial.

Tabla 1.

Resumen de hallazgos en Cataluña y Barranquilla: funciones del director comercial

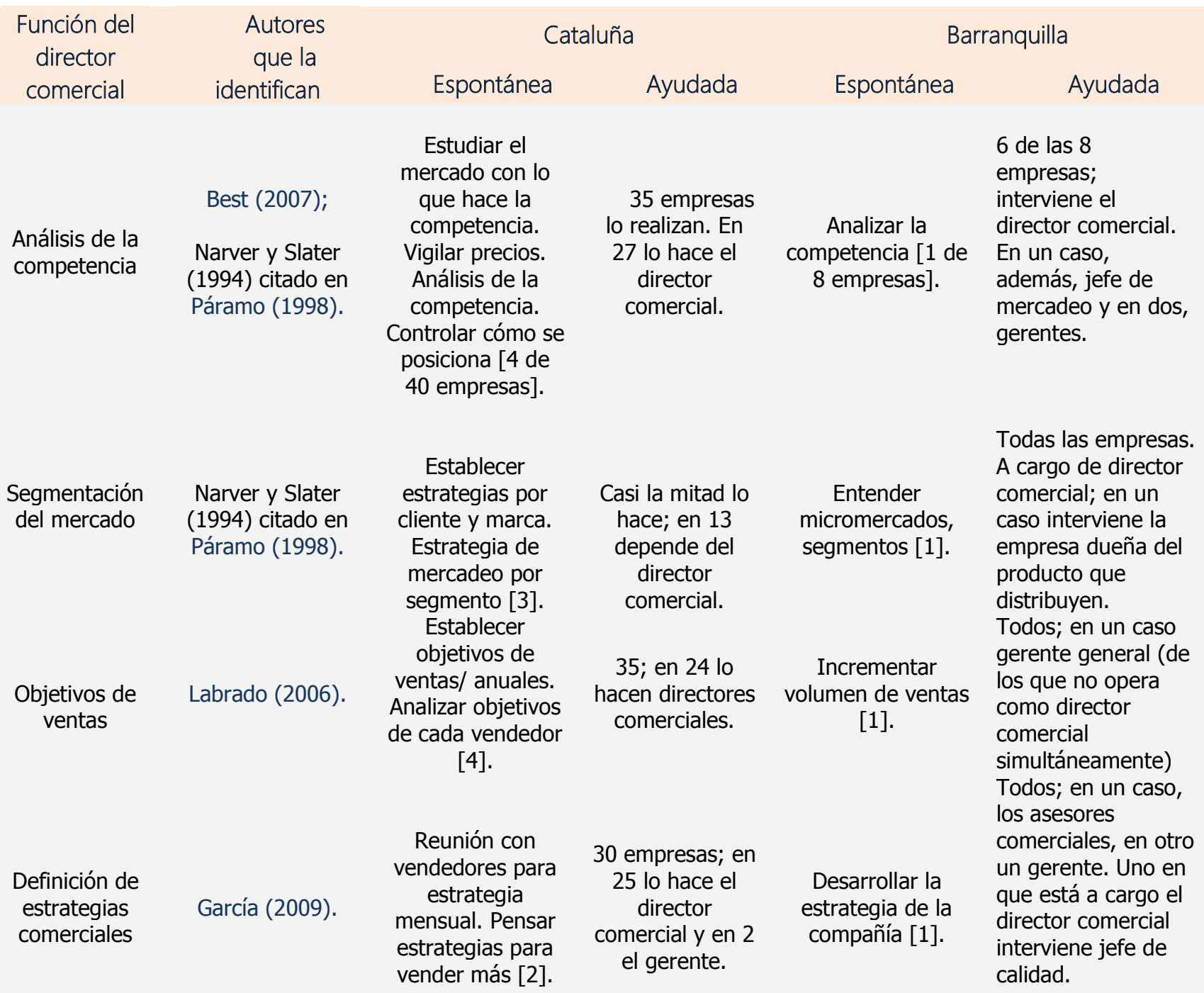




\section{Gestión de cartera de clientes}
Organización de la fuerza de ventas

Selección y contratación e inducción de vendedores

\section{Sistemas de retribución \\ Políticas de (1994); \\ Diez et al. (2003). Strafford y Grant (1994);} formación

Plan de acción comercial

Apoyo al equipo de ventas

Argumentarios de ventas

Manual de Strafford y Grant ventas

Control y evaluación

\section{Strafford y Grant (1994);}

Rubio (1999).

Strafford y Grant (1994);

Diez et al. (2003).

Strafford y Grant

Diez et al. (2003).

García (2009).

Diez et al. (2003); Labrado (2006).

Strafford y Grant (1994);

Rubio (1999). (1994).

\section{Artal (2016);}

García (2009);

Diez et al. (2003); Strafford y Grant (1994).
Gestionar/ hacer seguimiento/ visitar clientes propios [6]. Hacer seguimiento a clientes/ actuales [5].

\section{Gestionar la fuerza de ventas} [5].

Entrevistas de selección [3].

37; 27 el

comercial, en 4, recursos humanos.

39; en 34 el encargado es el director comercial.

Cursos de formación para los vendedores

[1].

Análisis con otros departamentos para plan de acción anual [1].

Motivar a los vendedores [2]. comerciales.

\section{2; en 20 director comercial.}

$11 ; 10$ es director comercial.

$13 ; 12$ directores comerciales.

5 , en 4 lo hace el director comercial.

Cumplir objetivos comerciales. Control de calidad, cobros, planeación, presupuestos/ de los vendedores.

39 directores comerciales.
23 directores

Mantenimiento de clientes. Apertura de clientes nuevos. Visitar clientes [6].

7; en varios casos jefe de cartera o tesorería.

Liderar a los vendedores [1].

Todos; interviene siempre el director comercial.

Todos; fuerte participación de recursos humanos. En un caso, supervisora de ventas y en otro, administradores de puntos de venta.

Incentivos a los

7; en varios casos gerente y en otros, director comercial.

Entrenamiento a los asesores [1]

La mitad; recursos humanos.

La mitad; director comercial, en un caso intervienen jefe de mercadeo y asesores.

Motivar a los vendedores. Acompañamiento [2].

6; a cargo de director comercial.

4; en un caso lo hace la empresa dueña del producto.

3 ; en uno lo hace el director de procesos.
Todos; suele encargarse el director comercial.

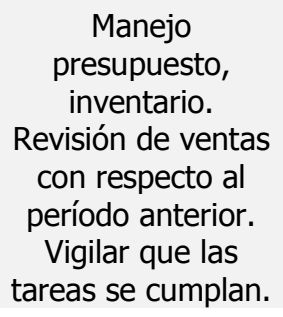
inventario.

Revisión de ventas con respecto al período anterior. Vigilar que las tareas se cumplan. 


\begin{tabular}{|c|c|c|c|c|c|}
\hline & & $\begin{array}{c}\text { Seguir indicadores } \\
\text { de rentabilidad } \\
\text { [12]. }\end{array}$ & & $\begin{array}{l}\text { Mejoramiento de } \\
\text { indicadores. Se } \\
\text { cumplan plazos de } \\
\text { entrega, con } \\
\text { calidad y precio } \\
\text { adecuados [8]. }\end{array}$ & \\
\hline $\begin{array}{l}\text { Participación } \\
\text { en ferias }\end{array}$ & $\begin{array}{c}\text { Strafford y Grant } \\
\text { (1994). }\end{array}$ & $\begin{array}{c}\text { Visitar ferias/ para } \\
\text { conocer mercado } \\
\text { [3]. }\end{array}$ & $\begin{array}{c}\text { 33; } 31 \\
\text { directores } \\
\text { comerciales, } 1 \\
\text { jefe de } \\
\text { mercadeo. }\end{array}$ & --- & $\begin{array}{l}6 \text { (en varios casos } \\
\text { como } \\
\text { compradores). En } \\
\text { una empresa lo } \\
\text { hace el jefe de } \\
\text { mercadeo, que } \\
\text { depende de la } \\
\text { dirección comercial. }\end{array}$ \\
\hline $\begin{array}{l}\text { Comunicación } \\
\text { externa }\end{array}$ & $\begin{array}{c}\text { Strafford y Grant } \\
\text { (1994); } \\
\text { Voirin (1998). }\end{array}$ & $\begin{array}{c}\text { Manejar la Web. } \\
\text { Sacar catálogos, } \\
\text { folletos. } \\
\text { Relaciones } \\
\text { públicas. Fijar } \\
\text { estrategia de } \\
\text { comunicación [6]. }\end{array}$ & $\begin{array}{c}\text { 36; } 28 \\
\text { directores } \\
\text { comerciales }\end{array}$ & $\begin{array}{c}\text { Atención a } \\
\text { gremios [1]. }\end{array}$ & $\begin{array}{c}\text { 7; en un caso, jefe } \\
\text { de mercadeo que } \\
\text { depende de } \\
\text { gerencia. }\end{array}$ \\
\hline $\begin{array}{l}\text { Análisis de } \\
\text { servicio } \\
\text { posventa }\end{array}$ & $\begin{array}{l}\text { Narver y Slater } \\
\text { (1994) citado en } \\
\text { Páramo (1998); } \\
\text { Diez et al. (2003); } \\
\text { Rubio (1999). }\end{array}$ & --- & $\begin{array}{c}\text { 20; director } \\
\text { comercial en } \\
\text { todos los casos. }\end{array}$ & $\begin{array}{l}\text { Servicio posventa. } \\
\text { Quejas y reclamos } \\
\text { de clientes [2]. }\end{array}$ & $\begin{array}{l}\text { 6; en un caso, jefe } \\
\text { de mercadeo. }\end{array}$ \\
\hline $\begin{array}{l}\text { Informes para } \\
\text { gerencia }\end{array}$ & Voirin (1998). & $\begin{array}{l}\text { Elaborar reportes/ } \\
\text { informes [2]. }\end{array}$ & 9 empresas. & $\begin{array}{l}\text { Informes para } \\
\text { la gerencia [2]. }\end{array}$ & $\begin{array}{l}\text { 5; director } \\
\text { comercial. }\end{array}$ \\
\hline $\begin{array}{c}\text { Nuevas } \\
\text { tecnologías } \\
(\mathrm{CRM})\end{array}$ & García (2009). & ---- & $\begin{array}{c}12 \\
\text { empresas. }\end{array}$ & --- & 3; gerencia. \\
\hline
\end{tabular}

\section{Conclusiones}

\section{Del trabajo en Cataluña.}

Los directores comerciales catalanes suelen 'hacer un poco de todo', dado que hay propietarios que ejercen como directores comerciales y también directores comerciales ajenos a la familia que se encuentran con la asignación de tareas que no corresponden con su función.

La función de mayor relevancia para los directores comerciales es la de control de su equipo de ventas, que está totalmente a su cargo. 
Los directores comerciales dedican más tiempo y esfuerzo a funciones relacionadas con la acción más que con la planificación y en algunos casos no las llevan a cabo porque no reciben apoyo de la dirección general. Cuando se planifica, mayoritariamente, es a corto plazo.

Hay mayor tendencia a que el departamento de mercadeo dependa de la gerencia general y no de la comercial si el director comercial no es miembro de la familia.

\section{Del trabajo en Barranquilla.}

Cuando los directores comerciales describen el cargo van al deber ser o a lo que sueñan hacer, que en parte es estratégico. Al describir funciones van al día a día, lo operativo y al mencionar una lista ayudada, en que hay funciones de ambas tendencias, llegan a un punto medio pues reconocen funciones que se hacen y las que no se hacen en la empresa y, en algunos casos, se dan cuenta de que la función sí se realiza pero de manera natural: no consciente o dentro de otros procesos.

\section{Del trabajo comparado entre Cataluña y Barranquilla.}

El director comercial ejerce funciones de mercadeo en ambos lugares.

Cuando el director comercial no es miembro de la familia que regenta el negocio, suele haber mayor interferencia del gerente general.

Objetivos de ventas y sistemas de retribución son temas en que el director general tiene injerencia en ambos lugares.

El sistema de retribución es ejercido en casi todas las empresas del estudio pero tiene poca mención espontánea; no se tiene presente.

Aunque en ambos lugares varias de las funciones en que se consume mucho tiempo son del día a día, en Barranquilla tienden a pensar un poco más en lo estratégico.

Las funciones que más se encontraron en la práctica fueron las planteadas por Strafford \& Grant (1994), caso de la organización de la fuerza de ventas, comunicación externa y sistemas de control; esta última también es incluida por otros autores como Artal (2016), García (2009) y Diez et al. (2003). 
En las empresas catalanas abordadas para el presente estudio planifican, organizan y controlan como lo registrado por Diez et al. (2003) pero no en todos los casos se realiza reclutamiento y actividades motivacionales. En Barranquilla hay menor tendencia al control y se busca motivar más, asunto que posiblemente tenga que ver con el aspecto cultural de ser una sociedad abierta y relajada, además de más nueva.

Asuntos hallados en estudios aplicados como el de Basco (2010), Pérez (2014) y Gómez et al. (2016) fueron corroborados, tal es el caso de la influencia de la familia en la empresa, especialmente del padre y de la forma como el dueño se encarga de muchas decisiones que marcan las funciones del director comercial. Por otra parte, no hay similitud con el de Wailerdsack y Suehiro (2004) pues en el presente estudio se encontró que en las empresas familiares sí se promueve el desarrollo profesional interno. Con respecto al análisis de Canales y Kuster (2008) se anota que para el presente estudio en Cataluña se encontró un poco más de funciones afines al control que en Barranquilla, pero en ambos lugares la presencia del director comercial en las visitas de su equipo de ventas son más para estimular la venta que para controlar. Cabe anotar que en ambas regiones los directores comerciales ejercen actividades de control al presupuesto de ventas.

\section{Referencias}

Artal, M. (2016). Dirección de ventas. 13a Ed. Madrid, España: ESIC Editorial.

Best, R. (2007). Marketing estratégico. 4a Ed. España: Pearson Prentice Hall.

Basco, R. (2010). Tipo de orientación familiar y prácticas de dirección y gobierno. Un estudio aplicado a las empresas familiares españolas. Revista Europea de Dirección y Economía de la Empresa. (19), 129-144. Recuperado de https://dialnet.unirioja.es/servlet/articulo?codigo=3185174

Bullemore, J. y Fransi, E. (2016). La gestión de las fuerzas de ventas, un estudio exploratorio a través del método Delphi aplicado a las empresas chilenas y propuestas de mejoras. Revista RAN Academia y Negocio, 2 (2), 1-16. Recuperado de http://ran.udec.cl/ojs/index.php/ran/article/view/33 
Canales-Ronda, P. y Küster-Boluda, I. (2008). Efectos del control del comportamiento en el desempeño del vendedor. La visión del jefe de equipo de ventas. Cuadernos de Economía y Dirección de la Empresa. (34), 135-156. DOI: https://doi.org/10.1016/S1138-5758(08)70056-2

Churchill, G. Ford, N. y Walker, O. (1994). Dirección de Ventas. $1^{\text {era }}$ Ed. Valencia, España: Promociones Jumerca.

Díaz-Valbuena, N. Leal-Guerra, M. Urdaneta-Montiel, A. (2018). ADN organizacional y productividad en las empresas familiares. Desarrollo Gerencial, 10(1), 105-122. DOI: https://doi.org/10.17081/dege.10.1.2987

Diez de Castro, E. Navarro-García, A. y Peral-Peral, B. (2003). Dirección de la fuerza de ventas. España: ESIC Editorial.

Fassio, A. (2018). Reflexiones acerca de la metodología cualitativa para el estudio de las organizaciones. Ciencias Administrativas, 6(12). 74-84. DOI: https://doi.org/10.24215/23143738e028

Gallo, M. (2004). Tipologías de las empresas familiares. Empresa y Humanismo (2), 241-258. Recuperado de $\quad$ https://www.unav.edu/publicaciones/revistas/index.php/empresa-yhumanismo/article/view/33340

Garavaglia, L. y Del Bene, L. (2017). Los gerentes no familiares en las pequeñas y medianas empresas familiares. Revista Ciencias Económicas, 14 (01), 141-164.

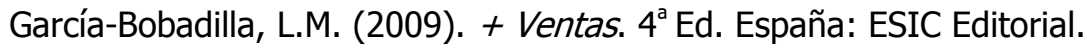

Gómez-Betancourt, G. Zapata-Cuervo, N. y Betancourt-Ramírez, J. (2016). Gobierno Corporativo. Prácticas sugeridas e implementadas por empresas familiares y no familiares colombianas. Entramado, 12(2), 12-29. DOI: http://dx.doi.org/10.18041/entramado.2016v12n2.24240

Guinjoan, M., Murillo, C. y Pons, J. (2004). L'empresa familiar a Catalunya, quantificació y característiques. Barcelona: CIDEM. 
Guiltinan, J. Gordon, P. y Madden, T. (1998). Gerencia de marketing: Estrategias y Programas. Bogotá, Colombia: McGraw-Hill.

Labrado, M. (2006). Misiones y responsabilidades de los puestos de trabajo. Selección, formación, organización y valoración de puestos. Barcelona: Ediciones Gestión 2000.

Lozano-Fuentes, L., Romero-González, M. y Hirsh, J. (2017). Sustentabilidad en la sucesión de las empresas familiares a través del modelo de los tres círculos y un modelo de sucesión. Desarrollo Gerencial, 9(2), 16-32. DOI: https://doi.org/10.17081/dege.9.2.2973

Manning, G. y Reece, B. (1997). Las ventas en el mundo actual. 6² Ed. México: Mc Graw Hill.

Martín-Santana, J. y Cabrera-Suárez, K. (2007). La gestión de marketing estratégico en la pequeña empresa familiar. Cuadernos de Gestión, 7 (1), 85-100. Recuperado de https://www.redalyc.org/articulo.oa?id=274320285005

Martínez-Miguélez, M. (2006). Ciencia y arte en la metodología cualitativa. México: Trillas.

Molina-Parra, P. Botero-Botero, S. Montoya-Monsalve, J. (2016). Empresas de familia: conceptos y modelos para su análisis. Pensamiento y Gestión, (41), 116-149. DOI: http://dx.doi.org/10.14482/pege.41.9704

Narver, J. \& Slater, S. (1994). Does a competitive environment moderate the marketing orientation performance relationship? Journal of Marketing, 58(1), 46-55. Recuperado de https://www.jstor.org/stable/1252250

Omaña-Guerrero, L. y Briceño Barrios, M. (2013). Gerencia de las empresas familiares y no familiares: análisis comparativo. Estudios Gerenciales, (29), 93-302. DOI: https://doi.org/10.1016/j.estger.2013.09.003

Páramo-Morales, D. (1998). Culturas organizaciones orientadas al mercado. Monografías de Administración (51). Bogotá, Colombia: Universidad de los Andes. 
Pérez-Lizaur, M. (2014). Las empresas familiares catalanas, chilenas y mexicanas: una comparación. Arxiu d'Etnografia de Catalunya, (14), 155-201. DOI: https://doi.org/10.17345/aec14.155-201

Ramos-Galarza, C. (2015). Los paradigmas de la investigación científica. Av. Psicol. 23(1), 9-17. Recuperado de http://www.unife.edu.pe/publicaciones/revistas/psicologia/2015_1/Carlos_Ramos.pdf

Rubio-Picón, C. (1999). Análisis y sistematización por categorías de la remuneración de la fuerza de ventas. (Tesis doctoral). Universidad de Sevilla, Sevilla, España.

Sánchez-Crespo, A. (2004). Cómo mejorar la estructura de la empresa familiar, guía práctica para empresarios. Córdoba: Cátedra PRASA de empresa familiar.

Santesmases-Mestres, M. (1999). Marketing, conceptos y estrategias. $4^{\text {a }}$ Ed. Madrid: Pirámide.

Stanfford, J. y Grant, C. (1994). Manual del director de ventas. 2a Ed. España: Ediciones Deusto.

Valdivia-Ubeda, A. (2011). Las funciones de la dirección comercial en la empresa familiar catalana (tesis doctoral). Universidad de Cádiz, Cádiz, España.

Voirin, G. (1998). Definir funciones y tareas en la empresa, 40 fichas tipo para evaluar la eficiencia. Bilbao, España: Deusto.

Wailerdsak, N. Suehiro, A. (2004). Top executive origins: comparative study between Japan and Thailand. Asian Business \& Management, (3), 85-104. DOI: https://doi.org/10.1057/palgrave.abm.9200071 